\title{
EL DISEÑO Y EL LÍMITE DE SU VALIDEZ. ENTRE LA ÉTICA AMBIENTAL Y LA ÉTICA CULTURAL
}

\author{
DESIGN AND ITS LIMIT OF VALIDITY BETWEEN \\ ENVIRONMENTAL AND GULTURAL ETHICS
}

\section{Tripaldi Toa}

Diseñadora con un Diplomado en Gerencia Estratégica de Mercadeo y un Máster en Diseño. Profesora e investigadora de la Universidad el Azuay desde el año 2003. Coordinadora de Investigación de la Facultad de Diseño de la UDA desde abril del 2013 a enero de 2017. Directora del Departamento de Comunicación y Publicaciones de la Universidad del Azuay desde febrero del 2017. Las líneas de investigación en las que más ha trabajado es la de la teoría y epistemología del diseño, con mucho énfasis en el tema de la semiótica, la evolución y el comportamiento social, relacionado a los elementos del diseño. También ha dirigido proyectos de desarrollo para la generación de productos editoriales para la Facultad de Diseño y la de la implementación de laboratorios de investigación para la misma Facultad.

ttripaldi@uazuay.edu.ec

orcid.org/0000-0002-3115-0170

\section{Galindo Ruht}

Diseñadora de Textil y Moda y Magíster en Diseño de la Universidad del Azuay de la ciudad de Cuenca, Miembro de Junta Académica de la Escuela de Diseño Textil y Moda de la Facultad de Diseño de la Universidad del Azuay. En los últimos 8 años ha dirigido proyectos de graduación cuyos enfoques se orientan hacia la investigación en temas de tecnología y producción textil, principalmente patronaje/moldería para indumentaria. Actualmente forma parte del equipo de trabajo en el proyecto de vinculación con la colectividad denominado: "Innovación a los tejidos de paja toquilla y alpaca en el Cantón Biblián".

mgalindo@uazuay.edu.ec

Fecha de recepción: 14 de enero, 2016 / Aceptación: 30 de junio, 2016. 


\section{Resumen}

El diseño como actividad y resultado de un proceso se relaciona con el contexto. Sin contexto no existe diseño, y es en esta íntima relación en que se marca la validez del producto. Se trata de un contexto complejo, definido por el ambiente y la cultura, un contexto que mantiene un equilibrio frágil. El artículo propone la urgencia de que el diseñador desarrolle su actividad profesional dentro de un marco ético, responsable con el contexto, para dejar de ser actor principal de su deterioro. Además, propone lineamientos dentro de los cuales un diseñador debería realizar su actividad para así ejercer una profesión más responsable con su medio.

Palabras clave: ambiente, contexto, cultura, ética, responsabilidad.

\section{Abstract}

Design as an activity and as the result of a process is related to its context. Without context there is no design. It is in this intimate relationship that the validity of a product is marked. This complex relationship, which is defined by the environment and culture, upholds a delicate balance. This article urges designers to develop their professional activity within an ethical framework. That is, being responsible with the context and not with its deterioration. In addition, the research presents guidelines within which designers should carry out their profession with a responsible stand with their context.

Keywords: environment, context, culture, ethics, responsibility. 


\section{INTRODUCCIÓN}

Desde el pensamiento crítico, la concepción del diseño ha dado un vuelco. El diseñador se involucra más con el contexto, no solamente para satisfacer las necesidades humanas o para lograr entrar en un mercado de ofertas y demandas, sino $y$, sobre todo, para conseguir una mayor responsabilidad ética en relación con el ambiente y con la cultura.

Actualmente la mayoría de profesiones poseen un código ético que norma sus actividades en relación con el contexto, con la moral, con los clientes, etc. En el campo del diseño existen muy pocas reglamentaciones a nivel internacional, y en Ecuador ni siquiera se ha planteado algo al respecto. El mayor problema de carecer de esta normativa ocurre cuando la actividad del diseño y sus productos resultantes se involucran con la cultura y el ambiente, ya que sus productos repercuten directamente en estos factores y pueden llegar incluso a afectarlos.

Lo que se pretende en este artículo es plantear lineamientos éticos que debería seguir el diseñador cuando sus productos supongan una relación con el ambiente y la cultura, desde la perspectiva bioética y la ética cultural. A pesar de que se reconoce la interrelación e interdependencia que existe entre el medio y la cultura, por motivos didácticos y por una postura teórica, hemos trabajado en propuestas separadas, que no difieren entre sí; al contrario, se encuentran y coinciden. Al tener cada una su espacio de análisis se logra profundizar en cada ámbito y concluir en propuestas más profundas.

\section{DISEÑO Y ÉTICA AMBIENTAL}

Uno de los grandes retos de la socie- dad actual es la protección del ambiente frente a la alarmante situación ambiental y a la necesidad cada vez más urgente de un cambio estructural en nuestro modelo social. El diseño, como práctica y como producto, es actor principal de esta realidad, por lo que resulta imperativo que su accionar disponga de lineamientos éticos responsables. Para proponer estos lineamientos hemos tomado como teoría central a la bioética desde el principio de responsabilidad de Hans Jonas (Acosta, 2002).

Jonas propone que es momento de crear una nueva ética, y que hay que iniciar por cambiar los imperativos éticos, sobre todo el imperativo kantiano que propone: "Actúa de tal manera que el principio de tu acción se transforme en una ley universal" (Jonas, cit. en Acosta, 2002, p. 90). En vez de esa ley, el autor propone un nuevo imperativo: "Actúa de tal modo que los efectos de tu acción sean compatibles con la permanencia de una vida humana auténtica" (Ib.). Esta nueva ética no debe ver solamente el bienestar humano, sino también el extrahumano, es decir, ampliar el horizonte e incorporar al concepto de bien humano el cuidado de la naturaleza.

El estado de la naturaleza extrahumana, toda la biosfera, está sometida a nuestro poder, habiéndose convertido en un bien cuya preservación pasó a estar bajo nuestra entera responsabilidad. Se ha transformado en una exigencia moral, ha adquirido derecho propio; más aún, su destrucción implicará la sentencia de muerte para la propia humanidad. Tenemos que considerar pues, que es indispensable agrandar el horizonte ético, lo cual significa no solamente considerar el bien humano, sino también el de 
la naturaleza extrahumana, que pasa a imponerse bajo la condición de un fin en sí mismo (lb., p. 107).

Ahora bien, ¿por qué es el ser humano el que debe responsabilizarse del cuidado de la naturaleza? El primer motivo es que ha sido responsable de su destrucción. Desde el inicio de la humanidad, ha poseído un poder extraordinario de transformación, ha tomado elementos de la naturaleza y los ha alterado para obtener herramientas que lo ayuden a tener un mejor nivel de vida y crear así lo que Manzini (1992) llama un "mundo artificial". Al continuar esta transformación y estar desprovisto de reglas que ordenen estas acciones humanas, el ser humano empezó una explotación desmedida de la naturaleza, hasta llegar a lo que hoy tenemos: una gran destrucción de la biósfera, altos niveles de deforestación, especies extintas y muchas en peligro de extinción, nuevas enfermedades humanas como el cáncer, entre otros efectos. Otro factor importante es la conciencia cada vez mayor que el ser humano adquirió sobre todos los daños que sus acciones han causado.

Es por esto que Jonas propone una nueva ética basada en el principio de responsabilidad del ser humano frente a la naturaleza: "La prescripción ética no se impone como coerción, sino como una fuerte exhortación dirigida a la libertad del agente de transformación. Y es justamente como una exhortación singular que la responsabilidad ética se convierte en sentimientos" (Acosta, 2002, p. 97). Esta nueva ética de responsabilidad no debe entenderse como normas que regulan las acciones de la humanidad desde el punto de vista legislativo, sino desde el punto de vista de los sentimientos; la humanidad debe sentirse afectivamente responsable de sus actos.
En ese marco, ¿qué responsabilidades debe asumir el diseñador? Si hablamos que el ser humano desde el inicio de la humanidad ha transformado la naturaleza para mejorar su calidad de vida y adaptarse a la naturaleza, y si aceptamos el hecho de que el diseño es "la concepción de productos elaborados por el ser humano, y es un instrumento para satisfacer necesidades y mejorar la calidad de vida" (Fiell \& Fiell, 2001, p. 4), podemos inferir que la humanidad ha realizado diseño desde su aparición, inicialmente de forma empírica y solo a partir de la revolución industrial de forma profesional.

Entonces el diseño y el diseñador, como actor principal de esta actividad, asume una total responsabilidad ante la naturaleza extrahumana y humana porque toda actividad que desempeña -tanto en el proceso de producción como en su utilización-y porque todos sus ámbitos de acción (gráfico, industrial, modas, interiores, arquitectura, etc.) repercuten en el espacio y el ambiente. El diseño transforma el mundo natural para formar un "mundo artificial". Sin embargo, desde siempre, el diseño también ha olvidado la naturaleza extrahumana y hasta ha tenido una posición indiferente ante los problemas que sus productos ocasionan al ambiente.

No obstante, la conciencia de que la calidad del medio es una de las responsabilidades sociales del diseñador no es un descubrimiento actual. Ya en los años setenta Gui Bonsiepe (citado en Burdek, 1994) propuso interpretar al diseño industrial como un medio que podría mejorar la calidad ambiental. En 1979, el Design Zentrum de Berlín (Ib.) realizó una descripción muy útil del diseño en el que se habló, entre otras cosas, de un diseño oportuno, es decir, un diseño que sirva para algo realmente importante y no sea simplemente un desperdi- 
cio de materiales, un diseño que no se limite a un producto, sino que también tome en cuenta la protección del medio, el ahorro energético, la posibilidad de reciclaje, durabilidad, etc.

Pero si hacemos un análisis de la actividad del diseñador y todos los problemas ambientales, podemos ver que estas ideas solo quedaron en papeles. Los proyectos de diseño solo han tomado en cuenta el mercado, el adelanto tecnológico o simplemente los intereses de grupos reducidos. Muchos proyectos se han planificado y han creado productos considerando estudios sobre el impacto al medio, pero han desestimado sus advertencias. Es por esto que es necesario contar con lineamientos éticos del diseño en relación con el ambiente, en los que se tome como teoría principal la ética de responsabilidad del medio propuesta por Hans Jonas, ya que el diseñador debe ser, verse y sentirse responsable de su actividad ante el medio y empezar a construir un mundo artificial que respete y viva en armonía y equilibrio con el mundo natural.

Manzini (1992) propone llegar a una nueva ecología del mundo artificial mediante una actitud ecológica del diseñador, una ecología que se constituya en un modo de pensar y de actuar, que oriente tanto el proceso de proyecto como el de producción. Propone adoptar un conjunto de referencias de valor, profundizar en temas específicos y utilizar instrumentos dentro del proyecto para lograr nuevos resultados que estén dentro de una visión de respeto. "La actitud ecológica del proyecto no debe significar solamente introducir nuevos parámetros y nuevas condicionantes en la usual actividad de proyecto, también significará pensar de forma diferente, plantear el proyecto sobre nuevas bases" (Manzini, 1992, p. 99).

Esto implica, entonces, pasar de una cultura del hacer productos sin límites ni reglas, a una cultura del hacer productos responsables. Implica un cambio profundo en la acción, donde no se incluya solo al diseñador, sino también a todos los actores que intervienen en el sistema del proyecto, el de producción y, con especial énfasis, el de consumo. Para lograr esto, Manzini (1992) afirma que es sustancial que los diseñadores despierten una sensibilidad a los problemas ecológicos generales, que entiendan los efectos ambientales que pueden ocasionar sus proyectos tanto a grandes como a minúsculas escalas, y que comprendan la gran responsabilidad que reposa en sus manos, que son transformadores del mundo natural.

Sin embargo, se puede llegar a pensar que si un diseñador trabaja dentro de un mundo de reglas y límites, se restringen las posibilidades de un trabajo creativo, libre y con adelantos tecnológicos. Es necesario cambiar esta idea. Hay que pensar la tarea del diseñador y sus límites desde el punto de vista de la responsabilidad social y global y tomar en cuenta que de su trabajo dependerá en buena medida el desarrollo y la permanencia de la vida humana y extrahumana. En lugar de considerar esta ética como una limitante creativa, se debe entenderla como un reto: proponer soluciones creativas, en ciertos casos, mucho más complejas que las soluciones comunes. Igualmente, Huidobro (2007), al desarrollar un manual de ética para el diseño en Chile, propuso que la idea no es ver esta responsabilidad desde el lado negativo, desde sus limitantes, desde lo que "no permitan hacer", sino apreciarla desde una perspectiva positiva, en la que el diseño contribuya a mejorar el entorno y la sociedad, a solucionar ciertos retos ambientales.

Algunos de los puntos importantes que se deberían tomar en cuenta en el diseño 
para lograr una ética de responsabilidad deberían ser:

- Al diseñar uno de los objetivos primordiales será el de ahorro de materiales, sobre todo si hablamos de materiales que pueden ser nocivos con el medio.

- El ahorro de energía debe ser primordial, así como el tipo de energía que se utilice, tanto en la fabricación del diseño como en su utilización, debe ser preferiblemente natural o no contaminante.

- Dentro de la elección de los materiales es necesario efectuar un análisis muy profundo de los daños que cada uno puede causar en el ambiente, y preferir aquellos reciclables, reutilizables y renovables.

- Generar diseños que sean capaces de cambiar y adaptarse a nuevas necesidades y contextos para lograr así la reducción de productos y, por consiguiente, también de basura.

- La cercanía entre el recurso natural, el diseñador y el usuario puede ayudar a la definición de objetos con características ambientales.

- Producir diseños que tengan no solamente la idea de una mercadotecnia verde, es decir, que transmitan un mensaje ecológico a través de su forma, sino también que enfaticen en utilizar materiales que contribuyan a mantener la estabilidad del medio.
- Diseñar objetos que imiten los ejemplos de la naturaleza para mantener los sistemas térmicos 0 de refrigeración, para de esta manera ahorrar energía mediante la utilización de la biotecnología y la biomimética.

- Procurar que los productos sean durables, resistentes, con una vida útil extensa, eliminando así la idea de que si un producto dura poco se puede vender más y aumentar así la riqueza de grupos reducidos. De esta manera se piensa solamente en el bienestar de unos pocos y en un bienestar efímero.

- Contribuir a fomentar los buenos hábitos de consumo de los productos.

- Educar al ser humano, ya que al ser comunicador dispone de una gran herramienta que, al ser bien utilizada, puede ayudar a mantener y mejorar el ambiente, mediante campañas de información, concientización y educación del estado actual del planeta y el correcto uso de los recursos.

\section{DISEÑO Y ÉTICA CULTURAL}

Para poder desarrollar lineamientos sobre una postura ética del diseño en relación con la cultura, es necesario primero estar claros sobre lo que entenderemos por cultura, identidad, ética cultural y diseño y cómo estas nociones se relacionan.

La palabra cultura cuenta con un sinnúmero de definiciones, se la puede entender como educación, clases sociales, expresiones ar- 
tísticas, entre otras; pero es mucho más que eso. La cultura define al ser humano, está presente en todas las personas, constituye un conjunto de relaciones entre ciertos sujetos y su mundo circundante, está conformada por creencias comunes, valores compartidos, formas de vida semejantes, comportamientos, costumbres y reglas de conducta parecidos. La cultura no es igual en todos los lugares del mundo, depende de las interrelaciones, del proceso de socialización en el que se adquiere, de la época en la que se desarrolla cada pueblo. La cultura está presente desde que el individuo nace y sigue presente hasta después de su muerte, es el ambiente en el cual toda persona crece y se desarrolla; por ello se puede decir con certeza que la cultura existe en todas partes, es lo que compartimos con los demás, son las destrezas, habilidades, creencias, conocimientos, maneras de expresar, sus costumbres, etc. (Malo \& Molinari, 1981).

La cultura no es estática, al contrario, está sujeta a cambios, cambios que se han dado durante toda la historia y que sirven como medio de adaptación a las exigencias del ser humano en relación con sus necesidades. Es más, se afirma que una cultura estática es una cultura muerta. Hoy en día la cultura está cambiando más rápidamente ya que está influenciada por la globalización, por lo que se discute el proceso del impacto y de los procesos de aculturación que aquello puede generar.

Dentro del estudio de la cultura no debemos olvidar uno de sus componentes más importantes: la identidad. "Con la expresión Identidad Cultural entendemos una variedad dotada de significado, un conjunto de diferencias que pueden ser leídas dentro de un contexto cultural determinado como un código lingüístico que se aparta de los demás" (Manzini,
1992, p.146). La identidad existe cuando un grupo humano se autodefine. Está presente en la vida cotidiana y en la cultura popular, es producto del devenir histórico y atraviesa distintas etapas, continuamente se está reproduciendo. Esto permite que se desarrolle y enriquezca 0 inclusive se debilite hasta desaparecer; pero es necesario que sea reconocida como tal por los demás. La identidad de un grupo no significa completa homogeneidad entre sus miembros, más bien se da una heterogeneidad o diversidad en su núcleo, pero con un predominio de lo común como regularidad (Castells, 2007).

El ser humano mantiene diversas actitudes y necesidades que provienen tanto de un mundo natural como de otro artificial; este mundo artificial es justamente el que ha creado la cultura. Las necesidades del ser humano nacen del mundo natural, pero su manera de satisfacerlas son parte de lo cultural. Una cultura satisface necesidades, cumple deseos y permite cumplir fines del ser humano; del grado en que mejor se cumplan estas funciones de expresar, dar sentido, integrar a una comunidad y asegurar el poder de las acciones, dependerá el tipo de cultura.

Hemos mencionado antes que la globalización constituye un factor de cambio de las culturas. Su objetivo primordial es conformar algo que podría llamarse cultura mundial, o sea, una sociedad con formas de vida semejantes, comportamientos, costumbres y reglas de conducta parecidas; pero esto no se ha dado. La globalización no ha logrado cancelar la diversidad, al contrario, ha desencadenado un fenómeno de reivindicación cultural, reivindicación de la diversidad. Y es justamente este hecho el que queremos relevar aquí. ¿Cómo debe actuar el diseñador en relación con las distintas culturas? 
Villoro (2007) nos explica que la ética solo puede referirse a comportamientos y disposiciones conscientes e intencionadas y, por eso mismo, solo tiene lugar en las personas. Luego, la ética y la moral son características propiamente humanas. Por eso mismo podemos hablar de una ética cultural. Para Villoro, esta ética de la cultura debería incluir tres puntos claves: (1) una ética de las creencias, esto es, de las maneras en cómo la voluntad debe incidir en la justificación, la adopción y el rechazo de las creencias comunes a una cultura; (2) una ética de las actitudes, que se pregunta por los valores a los que debería dar preferencia una cultura, y (3) una ética de las intenciones, que se ocupa de los fines que debe fijarse para una cultura y las acciones conformes con estos fines.

Además, existen dos puntos claves en los que se debe basar la ética cultural: el respeto y la responsabilidad hacia la propia cultura. El individuo debe conocer, entender, aceptar, sentir orgullo y luchar por la permanencia, importancia e integridad de su propia cultura y también debe respetar las otras culturas en su totalidad y responsabilizarse por su apropiación. ¿Cómo entra el diseño en todo esto?

Habíamos ya indicado en el tema del ambiente que el diseño está definido como "la concepción y planificación de todos los productos elaborados por el hombre, y se lo puede considerar como un instrumento para mejorar la calidad de vida y satisfacer las necesidades". (Fiell \& Fiell, 2001, p. 4). En consecuencia, se puede definir al diseño como un instrumento de la cultura para satisfacer las necesidades del ser humano. El diseño, entonces, es un resultado cultural. Dentro de estas apreciaciones estamos de acuerdo con Brandolini (citado en Burdek, 1994), quien expresa:
Pienso que el diseño hoy en día debe estar en situación de reflejar las condiciones históricas, culturales y tecnológicas. La tradición ya no se corresponde con la continuidad histórica, sino que se ha convertido en un continuo ir y venir de acontecimientos contradictorios ( $p$. 17).

Este último párrafo nos recuerda que la identidad no es estática, y en el diseño se debe tomar en cuenta todos los cambios que se puedan dar en determinado momento con la identidad y la cultura de un pueblo.

Erlhoff (citado en Burdek, 1994) afirma que el diseño debe siempre buscar un fin prácti$c 0, y$ esto lleva a que se tomen en cuenta cuatro requisitos básicos: debe ser funcional, significativo, concreto y contener un componente social. Dentro del componente social, debemos entender a la cultura en la que se desarrolla el diseño, para que este no solamente lleve una expresión de identidad, sino también para que sea aceptado, entendido y, por tanto, utilizado dentro de dicha cultura. Como se ha visto, el diseño está completamente ligado a la cultura, es más, es cultura y es por esta razón que las actividades del diseñador deben estar regidas por una ética en relación con la identidad y la cultura de los pueblos. Este hecho es sustancial si apreciamos que con la producción en serie se elaboran productos sin valor cultural o que simplemente intentan reproducir ciertos valores hegemónicos.

Claro que no debemos cerrar los ojos y rechazar los avances técnicos y tecnológicos que se descubren cada día, ya que mejoran nuestro nivel y calidad de vida y el desarrollo mismo de nuestros pueblos, pero sí debemos mantener nuestra identidad cultural. 
Se trata de aprender a dar a las ideas (y a las imágenes de las que son su vehículo) el peso y la duración que la materia como tal ya no garantiza. Sobre estas ideas hay que construir los nuevos criterios para diseñar y producir un mundo legible y capaz de comunicar significados profundos (Manzini, 1992, p. 150).

Como diseñadoras que somos, creemos que disponemos de elementos de juicio y de la capacidad necesaria para encontrar en nuestras culturas motivos de inspiración y reafirmación identitaria, con la responsabilidad de sujetarnos a normas de conducta morales claras e impecables, sabiendo que lo que se haga repercutirá en el presente y futuro de nuestra sociedad. Estamos claros que el diseño es cultura, y que puede ser utilizado como una herramienta cultural para modificar el entorno, que debe adaptarse a un modo de vida, expresar identidades, comunicarse, etc. Es indispensable, por tanto, que el diseñador se apropie de una ética cultural, es decir, que sea éticamente responsable y respetuoso sobre todo cuando utiliza elementos culturales propios y ajenos, para no caer en el abuso, irrespeto y apropiación indebida de la cultura. Y es éticamente responsable de que las culturas no desaparezcan, de asumir responsabilidad frente a procesos de aculturación y de que la cultura cumpla sus funciones de expresar emociones, deseos, modos de ver y de sentir el mundo, señalar valores, permitir preferencias y elecciones, dar sentido a actitudes y comportamientos e integrar a los individuos en un todo colectivo.

Podemos enumerar algunos lineamientos que aporten a la construcción de un diseño más responsable con la cultura:

- Diseñar objetos con excelencia con el fin de satisfacer las necesidades y mejorar el nivel de vida de la población; el diseñador debe esforzarse para alcanzar productos con estándares de calidad que respeten la tradición y la cultura.

- Realizar trabajos de investigación de campo mediante la observación y la participación activa para así tener presente la realidad cultural.

- Establecer claramente los límites entre culturas propias y ajenas, y realizar los procesos de apropiación cultural de una manera controlada, para evitar la aculturación y, en consecuencia, la desaparición de una cultura.

- Diseñar productos que fomenten el desarrollo y progreso de nuestros pueblos tomando como base primordial elementos identitarios propios de la cultura.

- Diseñar productos en los que se utilicen en lo posible elementos materiales propios de nuestra región.

- Diseñar productos acordes con el contexto cultural partiendo de la identidad.

- Investigar de manera profunda los elementos culturales y sus significados para evitar una utilización superficial e irrespetuosa de dichos elementos.

- El diseñador debe ser un actor importante dentro del ámbito de la glocalización, que es la apropiación a nivel local de los elementos globalizantes, es decir, reinterpretar y resignificar los elementos 
de fuera para que al relacionarse con nuestra identidad cultural esta no se pierda y, además, se integre de mejor manera al contexto.

- Reconocer que somos diversos y respetar esta realidad; esto implica diseñar objetos que permitan mantener una unidad armónica en medio de esta diversidad

\section{A MANERA DE CONCLUSIÓN}

El presente texto plantea la necesidad de que se norme la actividad del diseñador mediante leyes o códigos éticos y que existan entidades que vigilen su cumplimiento. También propone que el diseñador sea un agente educador, que inculque el respeto por el ambiente y la cultura. Sus planteamientos se apoyan en el hecho de que la actividad del diseñador posee un poder transformador $y$, por consiguiente, una fuerte responsabilidad con el entorno. En el momento en que el diseñador asuma, desde los sentimientos más profundos y vivos, que la protección del ambiente y que el contexto cultural forman parte de su obligación racional contribuirá a evitar que la destrucción planetaria y cultural continúe. "Se considera responsable, se siente afectivamente responsable, aquel a quien le es confiada la guarda de algo perecedero. ¿Y qué más perecedero que la vida que marcha hacia la muerte por la inconsecuente intervención del hombre?" (Ricoeur, citado en Acosta, 2002, p. 95). Ciertamente, la ética del diseño implica una reflexión, un análisis crítico sobre los ideales, valores y actuaciones morales de la conducta del diseñador. 


\section{REFERENCIAS BIBLIOGRÁFICAS}

Acosta, J. (2002). Bioética para la sustentabilidad. El principio de responsabilidad de Hans Jonas. La Habana: Publicaciones Acuario.

Burdek, B. (1994). Historia, teoría y práctica del diseño industrial. Barcelona: Gusto Gili.

Castells, M. (2007). Globalización, identidad y Estado en América Latina, Conferencia realizada en el Palacio de la Moneda, en Santiago de Chile en junio de 1999. Recuperado de: http://www.iadb.org/etica/Documentos/ abs_cas_globa.pdf.

Fiell, Ch. y Fiell, P. (2001). Design del siglo XX. Colonia: Taschen.

Hiudobro, M. (2007). Manual de ética para el Diseño. Recuperado de: http:// www.duoc.cl/formacion/documentos- $\mathrm{pdf} / \mathrm{fet} 00 /$ manual/diseno.pdf.

Malo, C. y Molinari, L. (1981). El Diseño en una Sociedad en Cambio. Cuenca: Centro Interamericano de Artesanías y Artes Populares, CIDAP.

Manzini, E. (1992). Artefactos. Madrid: Celeste Ediciones.

Villoro, L. (2007). Aproximaciones a una ética de la cultura. Recuperado de: http://www.complot1.com/52/articulo7.html 